\title{
The infection with
}

\section{new coronavirus SARS-CoV-2}

\author{
Gina GHEORGHE ${ }^{1,2}$, Florentina GHEORGHE ${ }^{3}$, Gabriela CEOBANU², Victor JUGANARU1, \\ Madalina ILIE ${ }^{1,2}$, Nicolae BACALBASA ${ }^{1,4}$, Ovidiu G. BRATU ${ }^{1,5,6}$, Camelia C. DIACONU ${ }^{1,2}$ \\ ${ }^{1}$ "Carol Davila“ University of Medicine and Pharmacy, Bucharest, Romania \\ ${ }^{2}$ Clinical Emergency Hospital of Bucharest, Bucharest, Romania \\ ${ }^{3}$ Medical Center As-AIDE Sante, Bucharest, Romania \\ 4"Ion Cantacuzino" Clinical Hospital, Bucharest, Romania \\ ${ }^{5}$ Emergency University Central Military Hospital, Bucharest, Romania \\ ${ }^{6}$ Academy of Romanian Scientists, Bucharest, Romania
}

\begin{abstract}
The new coronavirus, SARS-CoV-2, first identified in humans in Wuhan Province, China, in December 2019, has spread rapidly throughout the world, causing World Health Organization (WHO) to declare it a pandemic infection. This pathogenic agent belongs to the genus beta-coronavirus, alongside SARS (Severe Acute Respiratory Syndrome) and MERS (Middle East Respiratory Syndrome). The large number of infected patients is mainly due to the modality of transmission, through respiratory droplets. The most common manifestation of the disease/infection COVID-19 is pneumonia, as there are not any specific clinical manifestations that differentiate this disease from other respiratory viral infections. The confirmation of COVID-19 is done by RT-PCR (Real-Time Polymerase Chain Reaction) of respiratory specimens. In most cases, the damage induced by this infection is not severe, and death occurs most frequently among older patients or with significant comorbidities. To control this pandemic infection, measures such as self-isolation at home or quarantine are recommended. Given both the large number of infected patients, as well as the large number of deaths, it is imperative to conduct studies that identify effective therapeutic measures.
\end{abstract}

Keywords: coronavirus, SARS-CoV-2, COVID-19, pandemic, self-isolation

\section{INTRODUCTION}

Coronaviruses are a large family of zoonotic viruses which, transmitted to humans, cause diseases with varying degrees of severity, from a common cold to severe diseases, such as SARS (Severe Acute Respiratory Syndrome) or MERS (Middle East Respiratory Syndrome) [1]. In December 2019, in Wuhan, a province of China, a new strain of coronavirus (SARS-CoV-2) was identified in a group of patients presenting with viral pneumo- nia. Epidemiological investigation pinpointed that the common element among those patients was a visit to a Huanan market [2]. The virus was isolated from biological samples and classified as a beta-coronavirus, alongside SARS and MERS [2]. Since the first confirmed case with SARS-CoV- 2 infection, more than 150,000 cases and 5,000 deaths caused by this disease have been confirmed, with a mortality rate of about $3.4 \%$ [3]. In January 30 , 2020, the World Health Organization (WHO) declared the new coronavirus infection as a Public 
Health Emergency of International Concern (PHEIC) [4].

SARS was first identified in southern China in 2002. It caused over 8,000 illnesses and 774 deaths, with a mortality rate of $7 \%$ [5]. Another beta-coronavirus who was a public health problem was MERS; it was first identified in 2012, in Saudi Arabia, and did not cause the first outbreak of infection until two years later, in 2014 [6,7]. The number of confirmed cases of MERS worldwide was 2,494 and the number of deaths was 858 , with a mortality rate of $34.4 \%$ [8]. Figure 1 shows the relative impact of the three strains of coronavirus in terms of number of cases, number of deaths and mortality.

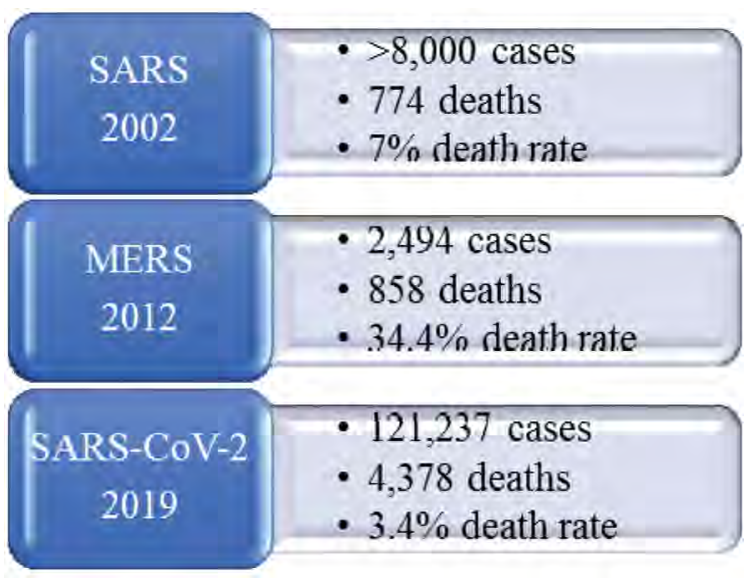

FIGURE 1. Number of cases, deaths and mortality rates caused by SARS, MERS and SARS-CoV-2 on March 11, 2020 [5-8]

\section{WAYS OF TRANSMISSION}

Interpersonal transmission was confirmed by identifying the presence of infection in several members of a family or among medical staff who cared for patients with COVID-19. The main way of transmission is represented by respiratory droplets or saliva drops. The virus released in the respiratory/saliva secretion (in situations of coughing, sneezing or only interpersonal communication) will thus contaminate other people if these particles come directly into contact with the mucous membranes, especially at the face level [9]. The respiratory/saliva droplets can be spread over a

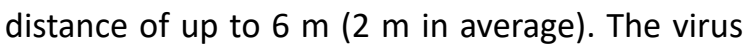
can be contacted directly from air, and indirectly from various contaminated surfaces, where it can survive several days [9]. The transmission can be done both from symptomatic and asymptomatic individuals, or patients being in the incubation period [10]. Although SARS-CoV-2was detected in samples of blood and stool, fecal-oral transmission does not seem to play a significant role in the spread of infection [11]. The incubation period is about 14 days, and in most cases, the symptoms appear within 4-5 days after primary infection [12]. A study that analyzed data from 181 patients infected with SARS-CoV-2, all reported in China, concluded that symptoms developed in $2.5 \%$ of those infected within 2.2 days and $97.5 \%$ of infected people in 11.5 days from the infection, the average incubation period being of 5.1 days [13]. A case with an incubation period of 19 days was reported [14]; also, Hubei Province local government declared a case with an incubation period of 27 days [15]. Under these circumstances and data, it can be concluded that the incubation period may vary between 2 and 27 days [15].

\section{DIAGNOSIS}

COVID-19 can affect all age groups, although middle-aged and elderly adults are most commonly affected. In a report by the Chinese Center for Disease Control and Prevention, $87 \%$ of patients were aged between 30 and 79 years [16]. If in children symptomatic infection is uncommon and usually mild, in the elderly COVID-19 is associated with a higher death rate compared to middle age adults who have the same disease [16]. Table 1 shows the fatality rate of COVID-19 by age [17]. The comorbidities also contribute to the death rate. Thus, in patients with cardiovascular disease the death rate was $10.5 \%$, in patients with diabetes $7.3 \%$, in patients with chronic respiratory diseases $6.3 \%$, in patients with arterial hypertension $6 \%$, and in patients with cancer 5.6\% [17].

TABLE 1. The fatality rate by age (adapted after [17])

\begin{tabular}{|c|c|}
\hline $\begin{array}{c}\text { Age } \\
\text { (years old) }\end{array}$ & $\begin{array}{c}\text { Death rate (all cases) } \\
\%\end{array}$ \\
\hline $80+$ & 14.8 \\
\hline $70-79$ & 8.0 \\
\hline $60-69$ & 3.6 \\
\hline $50-59$ & 1.3 \\
\hline $40-49$ & 0.4 \\
\hline $30-39$ & 0.2 \\
\hline $20-29$ & 0.2 \\
\hline $10-19$ & 0.2 \\
\hline $0-9$ & - \\
\hline
\end{tabular}

The most common manifestation of infection with SARS-CoV-2 is pneumonia. There are not any specific clinical manifestations that differentiate this disease from other respiratory viral infections [18]. The most common symptoms induced by the 
infection with SARS-CoV-2are shown in Table 2 $[19,20]$.

TABLE 2. Symptoms induced by the infection with SARS-COV-2

\begin{tabular}{|c|c|}
\hline \multicolumn{2}{|c|}{ Symptoms } \\
\hline Most common (\%) & Less common \\
\hline Fever (99) & Headache \\
\hline Fa (10) & Sore throat \\
\hline Dry cough (59) & Rhinorrhea \\
\hline Anorexia (40) & Gastrointes symptoms \\
\hline Myalgias (35) & \\
\hline Dyspnea (31) & \\
\hline Sputum prod (27) & \\
\hline
\end{tabular}

According to World Health Organization (WHO), a suspected case of SARS-CoV-2 infection is defined as a patient presenting with severe acute respiratory infection without an obvious cause and at least one of the following: history of travel in an area at risk, up to 14 days before the onset of symptoms, or medical personnel in a medical unit that is treating patients with severe acute respiratory infections of unknown etiology $[21,22]$. A confirmed case is the patient in whom the infection was identified by a SARS-CoV-2 laboratory test, regardless of the signs or symptoms $[21,22]$.

Regarding laboratory tests, SARS-CoV-2infected patients may present: leukopenia, leukocytosis, and lymphopenia, the most common being lymphopenia [23]. They also may have elevated aminotransferase levels. Procalcitonin levels are usually normal in patients with pneumonia but may be higher in patients who require intensive therapy [23]. In some studies, high levels of D-dimers and severe lymphopenia are associated with a higher mortality rate [24]. Chest CT examination most commonly reveals ground-glass opacification. Other changes that may occur are: pleural thickening, pleural effusion and lymphadenopathy. They are usually bilateral, have a peripheral distribution and involve the lower lobes $[25,26]$.

In patients suspected of being infected with the new coronavirus, it is recommended to test for both the pathogen agent, as well as other respiratory infectious agents. Thus, it is recommended that samples must be taken from the upper respiratory tract (nasopharyngeal and oropharyngeal swab) or lower respiratory tract (sputum, tracheal aspirates, or bronchoalveolar lavage). Additional biological samples, such as stool or urine, may be taken. Induced sputum collection is not recommended, and for safety reasons these samples will not be used in viral cultures. Identification of SARS CoV-2 RNA is performed by RT-PCR (Real-Time Polymerase Chain Reaction). A positive test confirms the infection, while a negative test cannot rule it out [9]. According to a report by the Chinese Center for Disease Control and Prevention, there are three degrees of damage induced by infection with SARS-CoV-2, listed in Table $3[16,27]$. In most cases, the damage caused by this infection is not severe and death generally occurs among patients who have significant comorbidities (cardiovascular disease $[28,29]$, diabetes [30,31], chronic respiratory disease, hypertension [32,33], cancer, etc).

TABLE 3. Severity of disease induced by SARS-CoV-2 infection

\begin{tabular}{|c|c|}
\hline Mild $-81 \%$ & No or mild pneumonia \\
\hline Severe $-14 \%$ & $\begin{array}{c}\text { dyspnea, hypoxia or }>50 \% \text { lung } \\
\text { involvement on imaging within 24 to } 48 \\
\text { hours }\end{array}$ \\
\hline calb $<5 \%$ & $\begin{array}{c}\text { respiratory failure, shock, orginn } \\
\text { dysfu }\end{array}$ \\
\hline
\end{tabular}

\section{MANAGEMENT}

To control this pandemic, measures such as early diagnosis, treatment and the quarantining of infected people to limit human-to-human transmission are recommended. In patients with mild impairment, the recommendations are self-isolation at home. In this situation, the main objectives are the limitation of infection transmission and self-health monitoring. In case of clinical deterioration, the patient requires hospitalization $[9,33$, 34].

For patients with severe symptoms, hospitalization is recommended, in order to implement measures of infection control and supportive care [9]. Glucocorticoids should not be used in case of pneumonia determined by SARS-CoV-2 without other indications, such as chronic obstructive pulmonary disease exacerbation. This medication was associated with increased mortality in patients with influenza and viral clearance delay in patients infected with MERS $[9,35]$. Studies until now have identified a number of potentially effective agents against SARS-CoV-2 (interferon- $\alpha$, lopinavir/ ritonavir, chloroquine phosphate, ribavirin, remdesivir, arbidol, favipiravir, darunavir) [3539]. Table 4 presents possible ways of administration of these drugs [38]. The recovery period is approximately 2 weeks for mild forms of infection and 3-6 weeks for severe forms of infection [9]. 
TABLE 4. Medication possibly effective in COVID-19 (adapted after Dong L et al. [37])

\begin{tabular}{|c|c|c|}
\hline Drug & Dosage treatment & Method of administration \\
\hline $\begin{array}{l}\text { Interferon- } \alpha \\
\quad(\text { IFN- } \alpha)\end{array}$ & $\begin{array}{c}5 \text { million } \mathrm{U} \text { or equivalent } \\
\text { dose }\end{array}$ & $\begin{array}{r}\text { Vapor inhala } \\
\text { s/day }\end{array}$ \\
\hline $\begin{array}{l}\text { Lopinavir/ } \\
\text { Ritonavir }\end{array}$ & $\begin{array}{l}200 \mathrm{mg} / 50 \mathrm{mg} / \text { capsule, } \\
2 \text { capsules e }\end{array}$ & $\begin{array}{l}\text { Oral } \\
\text { s/day }\end{array}$ \\
\hline Ribavirin & $\begin{array}{l}500 \mathrm{mg} \text {, in combina } \\
\text { with IFN- } \alpha \text { or lopinavir/ } \\
\text { ritonavir }\end{array}$ & $\begin{array}{c}\text { Intravenous infusion } \\
2 \mathrm{t} \quad \mathrm{s} / \text { day }\end{array}$ \\
\hline $\begin{array}{l}\text { Chloroquine } \\
\text { phosphate }\end{array}$ & $\begin{array}{l}500 \mathrm{mg} \text { (300 mg for } \\
\text { chloroquine) }\end{array}$ & $\begin{array}{l}\text { Oral } \\
\text { s/day }\end{array}$ \\
\hline Arbidol & $200 \mathrm{mg}$ & $\begin{array}{l}\text { Oral } \\
\text { s/day }\end{array}$ \\
\hline
\end{tabular}

\section{CONCLUSIONS}

The pandemic caused by the new coronavirus is the most important public health problem facing humanity at this time. Rapid transmission requires important prevention measures, such as self-isolation or quarantine in one's home. Studies to date have identified a number of therapeutic agents effective against SARS-CoV-2 in vitro. Given the disastrous situation, mainly through its effects on health and number of deaths, but also on the economies worldwide, further studies to elucidate the diagnostic and therapeutic possibilities are urgently required.

\section{REFERENCES}

1. De Wit E, van Doremalen N, Falzarano D, Munster VJ. SARS and MERS: Recent insights into emerging coronaviruses. Nat Rev Microbiol. 2016;14:523-534.

2. Zhu N, Zhang D, Wang W et al. A novel coronavirus from patients with pneumonia in China 2019. N Engl J Med. 2020; 382:727-733.

3. https://www.worldometers.info/coronavirus/ coronavirus-death-rate/ (accessed on 11 March 2020)

4. World Health Organization. Statement on the second meeting of the International Health Regulations (2005) Emergency Committee regarding the outbreak of novel coronavirus (2019-nCoV). 2020. Available at https://www.who.int/news-room/ detail/30-01-2020-statement-on-thesecond-meeting-of-the-international-healthregulations-(2005)-emergency-committeeregarding-the-outbreak-of-novelcoronavirus-(2019-ncov). Published January 31, 2020.

5. Anderson RM, Fraser C, Ghani AC et al. Epidemiology, transmission dynamics and control of SARS: the 2002-2003 epidemic Phil Trans R Soc Lond B. 2004; 359:1091-105.

6. Mackay IM, Arden KE. MERS coronavirus: diagnostics, epidemiology and transmission. Virol J. 2015;12:222.

7. Al-Omari A, Rabaan AA, Salih S, Al-Tawfiq JA, Memish ZA. MERS coronavirus outbreak: implications for emerging viral infections. Diagn Microbiol Infect Dis. 2019;93:265-85.

8. https://www.who.int/emergencies/mers-cov/ en/(accessed on 11 March 2020).

9. Mclntosh K. Coronavirus disease 2019 (COVID-19), UptoDate2020, (accessed on 11 March 2020). Available at https://www. uptodate.com/contents/coronavirusdisease-2019-covid-19\#H2513094760.

10. Li Z, Yi Y, Luo X et al. Development and clinical application of a rapid IgM-lgG combined antibody test for SARS-CoV-2 infection diagnosis. J Med Virol. 2020.

11. Report of the WHO-China Joint Mission on Coronavirus Disease 2019 (COVID-2019). February 16-24, 2020. http://www.who.int/ docs/default-source/coronavirus/ who-china-joint-mission-on-covid-19-finalreport.pdf (accessed on 04 March 2020).

12. Li Q, Guan X, Wu P et al. Early transmission dynamics in Wuhan, China, of novel coronavirus-infected pneumonia. $N$ Engl J Med. 2020.

13. Lauer S, Grantz KH, Bi Q et al. The incubation period of coronavirus disease 2019 (COVID-19) from publicly reported confirmed cases: estimation and application. Ann Intern Med. 2020.

14. Bai Y, Lingsheng Yao L, Wei T et al. Presumed asymptomatic carrier transmission of COVID-19. JAMA. 2020.

15. https://www.worldometers.info/coronavirus/ coronavirus-incubation-period/ (accessed on 15 March 2020).

16. Wu Z, McGoogan JM. Characteristics of and important lessons from the coronavirus disease 2019 (COVID-19) outbreak in China: Summary of a report of 72314 cases from the Chinese Center for Disease Control and Prevention. JAMA. 2020.

17. https://www.worldometers.info/coronavirus/ coronavirus-age-sex-demographics/ accessed on 15 March 2020).

18. Guan WJ, Ni ZY, Hu Y, et al. Clinical characteristics of coronavirus disease 2019 in China. N Engl J Med. 2020.

19. Wang D, Hu B, Hu C et al. Clinical characteristics of 138 hospitalized patients with 2019 novel coronavirus-infected pneumonia in Wuhan, China. JAMA. 2020.

20. Huang $C$, Wang $Y$, Li X et al. Clinical features of patients infected with 2019 novel coronavirus in Wuhan, China. Lancet. 2020; 395:497-506.

21. WHO. Clinical management of severe acute respiratory infection when novel
Conflict of interest: none declared Financial support: none declared coronavirus (2019-nCoV) infection is suspected. https://www.who.int/ publications-detail/clinical-management-ofsevere-acute-respiratory-infection-whennovel-coronavirus-(ncov)-infection-issuspected (accessed on 14 March 2020).

22. Peeri NC, Shrestha N, Rahman MS et al.The SARS, MERS and novel coronavirus (COVID-19) epidemics, the newest and biggest global health threats: what lessons have we learned? Int J Epidemiol. 2020; $1-10$.

23. Centers for Disease Control and Prevention. Interim clinical guidance for management of patients with confirmed 2019 novel coronavirus (2019-nCoV) infection. Updated February 12, 2020. https://www.cdc.gov/ coronavirus/2019-ncov/hcp/clinicalguidance-management-patients.html (accessed on February 14, 2020).

24. Chen N, Zhou M, Dong X et al. Epidemiological and clinical characteristics of 99 cases of 2019 novel coronavirus pneumonia in Wuhan, China: A descriptive study. Lancet. 2020; 395:507.

25. Zhao W, Zhong Z, Xie X et al. Relation between chest CT findings and clinical conditions of coronavirus disease (COVID-19) pneumonia: A multicenter study. AJR Am J Roentgenol. 2020;1-6.

26. Xie X, Zhong Z, Zhao W et al. Chest CT for typical 2019-nCoV pneumonia: relationship to negative RT-PCR testing. Radiology. 2020:200343.

27. Diaconu CC. A novel coronavirus threatens the world. Arch Balk Med Union. 2020; 55(1):11013.

28. Stoicescu M, Csepento C, Mutiu G, Bungau $S$. The role of increased plasmatic renin level in the pathogenesis of arterial hypertension in young adults. Rom $\mathrm{J}$ Morphol Embriol. 2011; 52(1 Suppl.):419-423.

29. Moisi MI, Rus M, Bungau S, Zaha CD, Uivarosan D, Fratila O, Tit DM, Endres L, 
Nistor-Cseppento DC, Popescu MI. Acute coronary syndromes in chronic kidney disease: Clinical and therapeutic characteristics. Medicina. 2020; 56(3):118. doi:10.3390/medicina56030118.

30. Abdel-Daim MM, El-Tawil OS, Bungau SG, Atanasov AG. Applications of antioxidants in metabolic disorders and degenerative diseases: Mechanistic approach. Oxid Med Cell Longev. 2019; 2019:1-3.

31. Popa AR, Bungau S, Vesa CM, Bondar AC, Pantis C, Maghiar O, Dimulescu (Nica) IA, Nistor-Cseppento DC, Rus M. Evaluating the efficacy of the treatment with benfotiamine and alpha-lipoic acid in distal symmetric painful diabetic polyneuropathy. Rev Chim. 2019; 70(9):3108-3114.

32. Vesa CM, Popa AR, Bungau S, Daina LG, Buhas C, Judea-Pusta CT, Pasca B, Dimulescu (Nica) I, Zaha DC. Exploration of insulin sensitivity, insulin resistance, early insulin secretion and $\beta$-cell function, and their relationship with glycated hemoglobin level in normal weight patients with newly diagnosed type 2 diabetes mellitus. Rev Chim. 2019; 70(12):4217-4223.

33. Popa AR, Vesa CM, Uivarosan D, Jurca CM, Isvoranu G, Socea B, et al. Cross sectional study regarding the association between sweetened beverages intake, fast-food products, body mass index, fasting blood glucose and blood pressure in the young adults from North-western Romania. Rev Chim. 2019; 70(1):156-160.

34. Diaconu C. Treatment of diabetes in patients with heart failure. The 3rd International Conference on Interdisciplinary Management of Diabetes Mellitus and Its Complications - Diabetes Melitus in Internal Medicine, INTERDIAB 2017 (Editors Serafinceanu C, Negoita O, Elian V). Proceedings, 170-177.

35. Centers for Disease Control and Prevention. Interim clinical guidance for management of patients with confirmed 2019 novel coronavirus (2019-nCoV) infection. Updated February 12, 2020. https://www.cdc.gov/coronavirus/2019- ncov/hcp/clinical-guidance-managementpatients.html (accessed on February 27, 2020).

36. Russell CD, Millar JE, Baillie JK. Clinical evidence does not support corticosteroid treatment for 2019-nCoV lung injury. Lancet. 2020; 395:473.

37. Gilead Sciences Statement on the Company's Ongoing Response to the 2019 Novel Coronavirus (2019-nCoV). https:// www.gilead.com/news-and-press/ company-statements/gilead-sciencesstatement-on-the-company-ongoingresponse-to-the-2019-new-coronavirus (accessed on February 02, 2020).

38. Dong L, Hu S, Gao J. Discovering drugs to treat coronavirus disease 2019 (COVID-19). Drug Discov Therapeutics. 2020;14(1):58-60.

39. Wang $M$, Cao $R$, Zhang $L$ et al. Remdesivir and chloroquine effectively inhibit the recently emerged novel coronavirus (2019-nCoV) in vitro. Cell Res. 2020; 30:269. 